Psychological Medicine, 1981, 11, 673-676

Printed in Great Britain

\title{
EDITORIAL
}

\section{Dementia, depression and the CT scan ${ }^{1}$}

Hounsfield's Nobel prize for the invention of computed tomography (CT) was well-deserved recognition of a major advance in medical technology, an innovation which produced immediate rewards in the diagnosis and management of space-occupying lesions (SOL), and justified high capital costs (Jacobsen et al. 1976; Thomson, 1977). However, for psychiatry, which is more concerned with trophic changes than SOL, the benefits of CT have not been fully defined. In dementia syndromes, for example, CT constitutes a marked improvement on pneumoencephalography (PEG) because of a greater and more easily obtained yield of information, but the clinical value of demonstrating cerebral atrophy in demented patients has not been fully established.

What information did PEG yield? The answer is not straightforward mainly because of methodological deficiencies, some of which, such as the lack of normative data, were due to ethical constraints. Thus, Burhenne \& Davies (1963) admitted that the 'normal' appearance on PEG is necessarily what the experienced radiologist considers not to be abnormal. Information from PEG was further limited by the risk of exacerbating dementia by the procedure itself. Nevertheless, it was agreed that clinically demented patients showed significantly more radiological atrophy than the non-demented (Chodoff et al. 1948; Wagner, 1951; Trolle \& Fog, 1951; Haug, 1962). In a follow-up study from a neurological hospital, Gosling (1955) showed that dementia was unlikely to be confirmed in the absence of radiological atrophy on clinical diagnosis. A consensus was also reached for the relative importance of ventricular enlargement over cortical (surface) atrophy (Chodoff et al. 1948; Wagner, 1951; Nielsen et al. 1966a, b), an observation confirmed by Mann (1973) in a follow-up study. In general, these findings were not invalidated by evidence for age-related ventricular enlargement (Burhenne \& Davies, 1963; Booker et al. 1969). An association between PEG atrophy and cognitive impairment was also demonstrated (McFie, 1960; Kiev et al. 1962; Nielsen et al. $1966 a$, b), but common psychological characteristics associated with cerebral atrophy could not be identified (Mathews \& Booker, 1972).

Prima facie direct visualization of the brain must be superior to merely outlining it with air, an opinion confirmed by the evidence. However, Jacoby et al. (1980) criticized the failure to realize the opportunity afforded by CT to obtain true normative data, a criticism based on the extensive use of patients found not to be abnormal rather than of healthy volunteers (Huckman et al. 1975; Gyldensted \& Kosteljanetz, 1976; Synek et al. 1976; Haug, 1977). More recently, data from non-patient controls have been published (Ron et al. 1979a; Jacoby et al. 1980). The clinical introduction of CT (Ambrose, 1973) was followed hastily by enthusiastic statements about its value in the diagnosis of dementia (Huckman et al. 1975; Fox et al. 1975; Menzer et al. 1975). Some of these authors have now confessed to unwarranted optimism (Fox et al. 1979). As with PEG, groups of demented patients exhibited significantly more atrophy than controls, but dementia occurred without atrophy and atrophy without dementia. In one study $16 \%$ of controls were found on blind rating to have enlarged ventricles, whereas $25 \%$ of dements had normal ventricles (Jacoby \& Levy, $1980 \mathrm{a}$ ). Overlap between the groups was confirmed by mean ventricle:skull ratio (dements $20 \cdot 6 \pm 5 \cdot 0$ s.D. cf. controls $14 \cdot 2 \pm$ 3.9 S.D.), although the difference between these means was highly significant $(P<0.001)$. Discriminant function analysis yielded an optimum prediction table in which $17 \%$ of cases were incorrectly assigned to their diagnostic group.

Although SOL tend to present to the neurologist, their exclusion in psychiatric patients is important as unforeseen tumours in psychiatric populations are well known (Waggoner \& Bagchi, 1954; Kraft et al. 1965). Jacoby \& Levy (1980a) found a corpus callosum glioma and a subdural haema-

1 Address for correspondence: Dr Robin Jacoby, Department of Psychiatry, The Middlesex Hospital, London W1N 8AA. 
toma, both clinically unsuspected, in 2 out of 40 scans of demented patients. In the same group, who were diagnosed before CT as senile (Alzheimer-type) dementia and carefully selected for absence of cerebrovascular disease, scans showed a significant excess of probable cerebral infarcts (one was confirmed at autopsy) compared with controls similarly selected to exclude cerebrovascular disease $(10 / 40 \mathrm{cf} .1 / 50, P<0.01)$. This finding not only underlined the clinical difficulty in differentiating Alzheimer-type from multi-infarct dementia (Radue et al. 1978) but also confirmed their frequent concurrence, which was demonstrated by the Newcastle neuropathological studies (Roth, 1971).

Attempts to show a reciprocal relationship between intellect and atrophy have met with only limited success. Roberts \& Caird (1976) found a high negative correlation between maximum ventricular area and performance on a simple test of cognitive function $(r=-0.49, P<0.01)$, but this correlation was effectively between atrophy and diagnosis since subjects ranged from nearly normal to severely demented. A correlation of the same order between ventricular area and a similar test of cognitive function $(r=-0.51, P<0.002)$ was found by Jacoby \& Levy $(1980 a)$ in an amalgamated group of healthy controls, depressed patients and dements. Within the group of dements alone, there were only weakly significant relationships or non-significant trends between psychological impairment and measures of ventricular enlargement, but not of cortical atrophy. Earnest et al. (1979) found significant correlations between poor test performance and atrophy (ventricular and cortical), but the association was weak, independent of age. Gado \& Hughes (1978) considered that atrophy was associated more with age than intellectual impairment; however, on the contrary, Jacoby \& Levy $(1980 a)$ found that demented patients under 80 had significantly larger ventricles than those of 80 years and over, which lead them to ask if early onset dementia might be a more malignant condition. A follow-up study to death of this sample is in progress and should help to clarify the issue. It is already clear, however, that subjects with marked parietal atrophy on CT have a significantly shorter life expectancy, thus supporting earlier clinical and neuropathological findings (McDonald, 1969; Constantinides, 1978). Age-related atrophy has been severally reported in normal subjects, but with wide variations of degree from striking (Barron et al. 1976) through moderate (Haug, 1977; Gyldensted, 1977) to non-significant trends (Gonzalez et al. 1978; Jacoby et al. 1980).

It is now clear that a diagnosis of primary neuronal dementia cannot be made on the basis of PEG or CT scan alone. This is especially true of PEG which may show spurious 'atrophy' due to relative dehydration, high oxygenation (by an anaesthetist) and consequent lowering of arterial $p \mathrm{CO}_{2}$. Two follow-up studies of patients originally diagnosed as presenile dementia underlined these clinical problems by demonstrating a high mis-diagnosis rate. Nott \& Fleminger (1975) found that 5 out of 15 patients in whom the diagnosis was not sustained over time had shown moderate cerebral atrophy on PEG at index admission, while Ron et al. $(1979 b)$ found that 8 out of 16 in the equivalent nondemented group had shown radiological atrophy. The misdiagnosed groups in both studies had exhibited considerable past and/or present affective symptoms at index admission. As far as CT and affective disorder is concerned, elderly depressed patients did not differ from controls on scan appearances alone (Jacoby \& Levy, 1980 b). However, the inadvisability of assuming that such patients are suitable as controls (vide supra) was shown both by comparison of true controls with affectives on a simple test of cognitive function, affectives performing significantly worse, and by comparison within the depressed sample. From the latter a subgroup was identified with enlarged ventricles who were older, whose depression was more 'endogenous' on the Newcastle Scale (Carney et al. 1965) and showed less anxiety on the Geriatric Mental State Schedule (Copeland et al. 1976; Gurland et al. 1976). Unpublished follow-up data indicate that this subgroup had a significantly higher mortality over two years from CT scan than depressives with normal ventricles ( 5 out of $9 \mathrm{cf} .4$ out of $31, P<0.03$ ), cause of death not being directly related to ventricular enlargement (Jacoby \& Levy, in preparation). Kay $(1959,1962)$ found that old age depression predicted a higher mortality than expected, and preliminary follow-up data on depressives and controls from the CT scan study (Jacoby et al. 1980) suggest that Kay's findings will be supported. With regard to affective disorder in the elderly, therefore, CT may be a useful prognostic indicator.

Until recently, CT has ploughed a furrow similar to that formerly dug by PEG, albeit wider and deeper, but future developments must involve a greater realization of CT's computerized potential. 
Since the output of the scanner is not a photographic plate but a matrix of numbers arranged according to anatomy, general volume and local radiodensity can be computed. Programs to determine ventricular volume already exist (Walser \& Ackerman, 1977; Brassow \& Baumann, 1978; Pentlow et al. 1978; Penn et al. 1978) and, with improvements, could be incorporated into the scanner's own software. Partial volume artefact (Jacoby et al. 1980) and distortions at high/low density interfaces, for example bone/CSF, have prevented measurement of brain volume itself, but such obstacles can be overcome. An approach qualitatively different from the assessment of cerebral atrophy is the measurement of radiodensity using an interactive method (Naeser et al. 1980). This gives an index of brain density and probably of tissue composition. If suitable areas of the brain can be reliably and consistently delineated, such radiodensity estimations could prove to be more useful in the clinical evaluation of dementia than computation of total brain or CSF volumes. These techniques are complicated and remain at present within the ambit of research, but if they prove to be of real clinical value there is no cogent reason why they cannot be transposed to the clinical domain.

ROBIN JACOBY

\section{REFERENCES}

Ambrose, J. (1973). Computerized transverse axial scanning (tomography): Part 2. Clinical application. British Journal of Radiology 46, 1023-1047.

Barron, S. A., Jacobs, L. \& Kinkel, W. R. (1976). Changes in size of normal lateral ventricles during aging determined by computerized tomography. Neurology 26, 1011-1013.

Booker, H. E., Mathews, C. G. \& Whitehurst, W. R. (1969). Pneumoencephalographic planimetry in neurological disease. Journal of Neurology, Neurosurgery, and Psychiatry 32, 241-248.

Brassow, F. \& Baumann, K. (1978). Volume of brain ventricles in man determined by computer tomography. Neuroradiology 16, 187-189.

Burhenne, H. J. \& Davies, H. (1963). The ventricular span in cerebral pneumography. American Journal of Roentgenology 90, 1176-1184.

Carney, M. W. P., Roth, M. \& Garside, R. F. (1965). The diagnosis of depressive syndromes and the prediction of ECT response. British Journal of Psychiatry 111, 659-674.

Chodoff, P., Simon, A. \& Freeman, W. (1948). Pneumoencephalographic diagnosis in the presenile dementias. American Journal of Roentgenology 59, 311-317.

Constantinides, J. (1978). Is Alzheimer's disease a major form of senile dementia? Clinical, anatomical and genetic data. In Alzheimer's Disease: Senile Dementia \& Related Disorders (ed. R. Katzman, R. D. Terry and K. L. Bick), pp. 15-25. Raven Press: New York.

Copeland, J. R. M., Kelleher, M. J., Kellett, J. M., Gourlay, A. J., Gurland, B. J., Fleiss, J. L. \& Sharpe, L. (1976). A semi-structured clinical interview for the assessment of diagnosis and mental state in the elderly: the Geriatric Mental State Schedule: I. Development and reliability. Psychological Medicine 6, 439-449.

Earnest, M. P., Heaton, R. K., Wilkinson, W. E. \& Manke, W. F. (1979). Cortical at rophy, ventricular enlargement and intellectual impairment in the aged. Neurology 29, 11381143.

Fox, J. H., Topel, J. L. \& Huckman, M. S. (1975). Use of computerized tomography in senile dementia. Journal of Neurology, Neurosurgery, and Psychiatry 38, 948-953.

Fox, J. H., Kaszniak, A. W. \& Huckman, M. (1979). Computerized tomographic scanning not very helpful in dementia - nor in craniopharyngioma. New England Journal of Medicine 300, 437.

Gado, M. \& Hughes, C. (1978). Cerebral atrophy and aging. Journal of Computer Assisted Tomography 2, 520.

Gonzalez, C. F., Lantieri, R. L. \& Nathan, R. J. (1978). The CT scan appearance of the brain in the normal elderly population: a correlative study. Neuroradiology 16, 120122.

Gosling, R. H. (1955). The association of dementia with radiologically demonstrated cerebral atrophy. Journal of Neurology, Neurosurgery, and Psychiatry 18, 129-133.

Gurland, B. J., Fleiss, J. L., Goldberg, K., Sharpe, L., Copeland, J. R. M., Kelleher, M. J. \& Kellett, J. M. (1976). A semi-structured clinical interview for the assessment of diagnosis and mental state in the elderly: the Geriatric Mental State Schedule. II. A factor analysis. Psychological Medicine 6, 451-459.

Gyldensted, C. (1977). Measurements of the normal ventricular system and hemispheric sulci of 100 adults with computed tomography. Neuroradiology 14, 183-192.

Gyldensted, C. \& Kosteljanetz, M. (1976). Measurements of the normal ventricular system with computer tomography of the brain: a preliminary study on 44 adults. Neuroradiology 10, 205-213.

Haug, G. (1977). Age and sex dependence of the size of normal ventricles on computed tomography. Neuroradiology 14, 201-204.

Haug, J. O. (1962). Pneumoencephalographic studies in mental disease. Acta psychiatrica scandinavica Supplement 165.

Huckman, M. S., Fox, J. \& Topel, J. (1975). The validity of criteria for the evaluation of cerebral atrophy by computed tomography. Radiology 116, 85-92.

Jacobsen, H. H., Kragsholm, M. \& Holm, C. (1976). The economy of the E.M.I. scanner. Neuroradiology 11, 183184.

Jacoby, R. J. \& Levy, R. (1980a). Computed tomography in the elderly: 2 . Senile dementia: diagnosis and functional impairment. British Journal of Psychiatry 136, 256-269.

Jacoby, R. J. \& Levy, R. $(1980$ b). Computed tomography in the elderly: 3. Affective disorder. British Journal of Psychiatry 136, 270-275.

Jacoby, R. J., Levy, R. \& Dawson, J. M. (1980). Computed tomography in the elderly: 1. The normal population. British Journal of Psychiatry 136, 249-255.

Kay, D. W. K. (1959). Observations on the natural history and genetics of old age psychoses: a Stockholm material, 1931-1937 (abridged). Proceedings of the Royal Society of Medicine 52, 791-794.

Kay, D. W. K. (1962). Outcome and cause of death in mental disorders of old age: a long-term follow-up of functional and organic psychoses. Acta psychiatrica scandinavica 38, 249-276.

Kiev, A., Chapman, L. F., Guthrie, T. C. \& Wolff, H. G. (1962). The highest integrative functions and diffuse cerebral atrophy. Neurology 12, 385-393. 
Kraft, E., Schillinger, A., Finby, N. \& Halperin, M. (1965). Routine skull radiography in a neuropsychiatric hospital. American Journal of Psychiatry 121, 1011-1012.

McDonald, C. (1969). Clinical heterogeneity in senile dementia. British Journal of Psychiarry 115, 267-271.

Mann, A. H. (1973). Cortical atrophy and air encephalography: a clinical and radiological study. Psychological Medicine 3, 374-378.

Mathews, C. G. \& Booker, H. E. (1972). Pneumoencephalographic measurements and neuropsychological test performance in human adults. Cortex 8, 69-92.

McFie, J. (1960). Psychological testing in clinical neurology. Journal of Nervous and Mental Disease 131, 383-393.

Menzer, L., Sabin, T. \& Mark, V. H. (1975). Computerized axial tomography: use in the diagnosis of dementia. Journal of the American Medical Association 234, 754-757.

Naeser, M. A., Gebhardt, C. \& Levine, H. L. (1980). Decreased computerized tomography numbers in patients with presenile dementia: detection in patients with otherwise normal scans. Archives of Neurology 37, 401-409.

Nielsen, R., Petersen, O., Thygesen, P. \& Willanger, R. $(1966 a)$. Encephalographic ventricular atrophy: relationships between size of ventricular system and intellectual imparrment. Acta radiologica Diagnosis 4, 240-256.

Nielsen, R., Petersen, O., Thygesen, P. \& Willanger, R. $(1966 b)$. Encephalographic cortical atrophy: relationships to ventricular atrophy and intellectual impairment. Acta radiologica Diagnosis $4,437-448$.

Nott, P. N. \& Fleminger, J. J. (1975). Presenile dementia: the difficulties of early diagnosis. Acta psychiatrica scandinavica 51, 210-217.

Penn, R. D., Belanger, M. G. \& Yasnoff, W. A. (1978). Ventricular volume in man computed from CAT scans. Annals of Neurology 3, 216-223.

Pentlow, K. S., Rottenberg, D. A. \& Deck, M. D. F. (1978). Partial volume summation: a simple approach to ventricular volume determination from CT. Neuroradiology 16, 130132.

Radue, E. W., Du Boulay, G. H., Harrison, M. J. G. \& Thomas, D. J. (1978). Comparison of angiographic and
CT findings between patients with multi-infarct dementia and those with dementia due to primary neuronal degeneration. Neuroradiology 16, 113-115.

Roberts, M. A. \& Caird, F. I. (1976), Computerised tomography and intellectual impairment in the elderly. Journal of Neurology, Neurosurgery and Psychiatry 39, 986-989.

Ron, M. A., Acker, W. \& Lishman, W. A. (1979 a). Dementia in chronic alcoholism: a clinical, psychological and computerised axial tomographic study. In Biological Psychiatry Today (ed. J. Obiols, C. Ballus, E. Gonzalez Monclus and J. Pujol), pp. 1446-1450. North-Holland Biomedical Press : Amsterdam.

Ron, M. A., Toone, B. K., Garralda, M. E. \& Lishman, W. A. $(1979 b)$. Diagnostic accuracy in presenile dementia. British Journal of Psychiatry 134, 161-168.

Roth, M. (1971). Classification and aetiology of mental disorders of old age: some recent developments. In Recent Development in Psychogeriatrics (ed. D. W. K. Kay and A. Walk), pp. 1-18. Headley Bros.: Ashford.

Synek, V., Reuben, J. R. \& Du Boulay, G. H. (1976). Comparing Evans' index and computerised axial tomography in assessing relationship of ventricular size to brain size. Neurology 26, 231-233.

Thomson, J. L. G. (1977). Cost-effectiveness of an EMI brain scanner: a review of a 2-year experience. Health Trends 9 , 16-19.

Trolle, E. \& Fog, M. (1951). Encephalography in nonsurgical neurological diagnostic. Acta psychiatrica scandinavica Supplement 74, 193-198.

Waggoner, R. W. \& Bagchi, B. K. (1954). Initial masking of organic brain changes by psychic symptoms. American Journal of Psychiatry 110, 904-910.

Wagner, F. F. (1951). Brain atrophy in a psychiatric clinic diagnosed by pneumoencephalography. Acta psychiatrica scandinavica Supplement 74, 212-215.

Walser, R. L. \& Ackerman, L. V. (1977). Determination of volume from computerized tomograms: finding the volume of fluid-filled brain cavities. Journal of Compurer Assisted Tomography 1, 117-130. 